\title{
Active Wnt signalling is associated with low differentiation and high proliferation in human biliary tract cancer in vitro and in vivo and is sensitive to pharmacological inhibition
}

\author{
TOBIAS KIESSLICH ${ }^{1}$, BEATE ALINGER ${ }^{2}$, GERNOT W. WOLKERSDÖRFER ${ }^{1}$, \\ MATTHIAS OCKER ${ }^{3}$, DANIEL NEUREITER ${ }^{2}$ and FRIEDER BERR ${ }^{1}$ \\ ${ }^{1}$ Department of Internal Medicine I, ${ }^{2}$ Institute of Pathology, Paracelsus Medical University/ \\ Salzburger Landeskliniken (SALK), Muellner Hauptstrasse 48, 5020 Salzburg, Austria; \\ ${ }^{3}$ Institute of Surgical Research, Philipps-University Marburg, Baldingerstrasse, 35033 Marburg, Germany
}

Received August 24, 2009; Accepted October 5, 2009

DOI: 10.3892/ijo_00000474

\begin{abstract}
Activation of developmental pathways has been recognized as a key mechanism for tumourigenesis and, hence, might be a valuable target for otherwise difficult to treat tumour entities such as biliary tract cancer (BTC). Therefore, we performed a comprehensive analysis of the Wnt signalling pathway in 9 BTC cell lines on cell blocks, xenograft tumours and on human tissue microarrays by realtime reverse transcription PCR and by immunochemistry. Furthermore, the effects of pharmacological pathway inhibition were investigated. As a result we found a significant positive correlation of Wnt pathway activation with cyclin D1 expression and the proliferation parameters Ki67, cell cycle distribution, and growth kinetics as well as the mesenchymal marker vimentin and an inverse correlation with E-cadherin in BTC cell lines in vitro and in vivo. In human BTC samples loss of membranous $\beta$-catenin, an indicator of active Wnt signalling, correlated with vimentin expression and advanced tumour stage or metastasis, whereas membranous localisation of $\beta$-catenin was associated with the differentiation marker cytokeratin-8/18 and differentiated tumour morphology (ductal or mixed type BTC). In addition, Wnt pathway inhibition by DMAT effectively reduced viability in all cancer cell lines, most effectively in those showing cytoplasmatic B-catenin localisation, i.e. active Wnt signalling. In summary, activation of the Wnt pathway is associated with high proliferation, dedifferentiation and a solid morphology in human biliary tract cancer cell lines both in vitro and in vivo, and in
\end{abstract}

Correspondence to: Dr Frieder Berr, Department of Internal Medicine I, Paracelsus Medical University/SALK, Muellner Hauptstrasse 48, 5020 Salzburg, Austria

E-mail: f.berr@salk.at

Key words: biliary tract cancer, Wnt signalling pathway, proliferation, differentiation, pathway inhibition human BTC tissues. Further investigation of the mechanism(s) of Wnt pathway activation and its inhibition may provide new molecular treatment strategies for biliary tract cancer.

\section{Introduction}

Biliary tract cancer (BTC) still has a poor prognosis. The only curative treatment is surgical resection with a median 5 -year survival rate of only $35 \%(1,2)$. In the majority of patients $(70-80 \%)$, however, local tumour extension or metastases preclude complete resection. For non-resectable BTC, palliative chemo/radiochemotherapy or photodynamic tumour ablation achieve median survival times up to 18 to 28 months (2-4). These therapies, however, fail to inhibit BTC tumour cell proliferation in the long-term. Molecular growth characteristics, and pharmacologic inhibitors, of BTC could indicate potential targets for molecular therapy in this orphan tumour disease.

Recent studies highlight a role of developmental signalling pathways for tumourigenesis demonstrating that tumour cells employ these signalling mechanisms for cell proliferation and metastasis $(5,6)$. Developmental pathways such as hedgehog and Wnt exert specific pathway-dependent effects on expression of genes involved in gastrointestinal tumourigenesis $(7,8)$. The Wnt pathway is critical to embryonic development in a variety of organisms by controlling the expansion of cells with predefined fates (9). The most wellknown example for involvement of Wnt signalling in tumourigenesis is adenomatous polyposis coli where the responsible germline mutation affects the gene for APC (adenomatous polyposis coli), a central regulatory component of the Wnt pathway (10). In subsequent studies, the involvement of deregulated Wnt signalling could be demonstrated in a variety of other tumours based on the discovery of mutations in other components of the pathway such as axin and $\beta$-catenin (ßCat) (11). Active Wnt signalling usually results in cytoplasmatic stabilisation of $B$ Cat leading to the accumulation and nuclear translocation of BCat where it complexes with the $\mathrm{T}$ cell factor/lymphoid enhancer-binding factor $(\mathrm{TCF} / \mathrm{LEF})$ and induces transcription of Wnt target genes 
(11-13). This type of canonical Wnt signalling is regularly initiated by binding of one of the 19 to date known secreted Wnt proteins (14) to two distinct membrane receptors, i.e. the frizzled proteins (Frz) and low-density lipoprotein receptor related proteins (LRPs). Receptor activation inactivates a destruction complex consisting of APC, axin and GSK3 (glycogen synthase kinase 3) thus preventing the phosphorylation of BCat by GSK3, its ubiquitinylation and, eventually, proteasome-mediated degradation (reviewed in ref. 13). The role of Wnt signalling in tumourigenesis is based on transcriptional activation of targets relevant to tumour initiation and progression. These include cyclins and c-myc, antiapoptosis factors such as survivin and transcription factors such as Snail or Slug inducing epithelial-to-mesenchymal transition (EMT) or matrix metalloproteinases for tumour invasion and metastasis (15). Therefore, targeting the Wnt pathway has been suggested to represent a promising antitumour strategy $(16,17)$.

As BTC is an orphan tumour, well-characterized preclinical models are of great value for identification of novel therapeutic targets. As the Wnt pathway has not been studied systematically in BTC, we investigated, whether the Wnt canonical pathway is expressed and plays a major role in the growth potential and de-/differentiation characteristics of biliary tract cancer cells in vitro (in nine BTC cell lines) and in their corresponding xenograft tumour model. In addition, in tissue microarrays (TMA) of human BTC we studied the expression of Wnt pathway activation related to tumour differentiation grade and clinical staging of the original tumour. The aim was, to study the role of the Wnt pathway for progression of BTC and analyse the effects of its inhibition in this model system.

\section{Materials and methods}

Substances, cell lines and culture conditions. DMAT (2dimethylamino-4,5,6,7-tetrabromo-1H-benzimidazole; Wnt inhibitor), PI and RNase (propidium iodide and ribonuclease A; cell cycle analysis), MTT (3-(4,5-dimethyl-2-thiazolyl)2,5-diphenyl-2H-tetrazolium bromide; cytotoxicity assay), crystal violet and glutaraldehyde (growth assay) were obtained from Sigma-Aldrich (Vienna, Austria). Bile duct carcinoma cell lines CCLP-1 (18), CCSW-1 (18), BDC (19), Egi-1, SkChA-1 (20), TFK-1 (21) and gallbladder cancer cell lines MzChA-1 (20), MzChA-2 (20), Wittier (22) were cultured as described previously (23) using Dulbecco's modified Eagle's medium (DMEM) supplemented with $10 \%(\mathrm{v} / \mathrm{v})$ fetal bovine serum (FBS; PAA Laboratories, Pasching, Austria). Cell lines and human tissue samples are collectively referred to as biliary tract cancer (BTC) in the following (24). See Table I for original tumour grading.

Quantitative real-time RT-PCR. Cells were lysed by addition of TRIzol reagent (Invitrogen, Lofer, Austria) to $10 \mathrm{~cm}$ diameter petri dishes and total RNA was isolated according to the manufacturer's instructions. An aliquot was subsequently subjected to DNase treatment and reverse transcription (RQ RNase-Free DNAse and ImProm-II RT system, Promega, Mannheim, Germany) using random primers (Invitrogen), according to the manufacturer's instructions. Quantitative real-time reverse transcriptase-PCR (qRT-PCR) was employed to analyze expression of Wnt-specific mRNAs coding for ligands (Wnt1/3/3a/8a), receptors (Frz1/3/7), and transcription factors [Lef-1, Tcf7, Tcf7L1/2; lymphoid enhancerbinding factor 1 , transcription factor 7 (-like1/2, T cellspecific)] using an iCycler real-time PCR thermocycler (BioRad Laboratories, Hercules, CA). Identity and specificity of the product were checked by polyacrylamid gel-electrophoresis/silver stain and by negative first-deviation plots of the melting curve, respectively. Calculation of the relative expression of each transcript $(\mathrm{X})$ was performed using the formula $2^{-\Delta \mathrm{Ct}}(25)$, where $\Delta \mathrm{Ct}=\mathrm{C}_{\mathrm{t}(\mathrm{x})}-\mathrm{C}_{\mathrm{t}(\mathrm{H})}$ with polymerase (RNA) II (DNA directed) polypeptide A as the housekeeping gene $(\mathrm{H})$ (26). Primer sequences are available on request.

Cell cycle analysis and growth assay. Cellular DNA content was analyzed using a FACSCanto II flow cytometer as described previously (27) (BD Biosciences, Schwechat, Austria; data analysis: WinMDI software Version 2.8). For growth analysis cells were seeded at a density of $1 \times 10^{4}$ per well in 96-well transparent microplates (Greiner Bio-One, Kremsmünster, Austria) in $100 \mu 1$ DMEM (10\% FBS). The crystal violet assay was used to assess the change in cell mass (proliferation) as described (28). Absorbance was read using an Infinite M200 microplate reader (Tecan, Groedig, Austria) at $590 \mathrm{~nm}$, corrected by subtraction of blank values (wells treated as above, without cells) and related to the initial time point set to $1(100 \%)$.

Cell block. Cell pellets were resuspended in $200 \mu \mathrm{l}$ citrate plasma (supplied by the Institute of Transfusion Medicine, PMU, Salzburg, Austria) and $200 \mu 1$ Thromborel ${ }^{\circledR}$ S (Siemens Healthcare Diagnostics, Deerfield, IL, USA). After coagulation cells were fixed for $1 \mathrm{~h}$ in neutral-buffered saline containing $7 \%$ formalin and were then paraffin-embedded.

Xenograft model. Cell lines were harvested, resuspended in sterile physiologic $\mathrm{NaCl}$ solution and injected into the flank of 4 to 6 -week old NMRI mice (each $3 \times 10^{6}$ cells per mouse/5 mice per cell line; Harlan Winkelmann $\mathrm{GmbH}$, Borchen, Germany) (29,30). Animals were kept in a lightand temperature-controlled environment and provided with food and water ad libitum. Animals were sacrificed at mean day 45 (range 39-46) by cervical dislocation and tumour samples were fixed in $10 \%$ phosphate-buffered formalin. Ethical approval was granted before any animal experiment by the Regional Government of Lower Franconia, Würzburg, Germany (No. 54-2531.31-9/06).

Histology. Hematoxylin-eosin (H\&E) staining was used to evaluate basic histomorphology of the specimens, especially ductal and solid morphology which was assigned if the tumour displayed ductal and solid formations in $>75 \%$ of the whole specimen, respectively. The epithelial mucopolysaccharides were detected by the PAS reaction (score 0-3: 0 for negative, 1 for low (0-25\%), 2 for moderate (25-50\%) and 3 for strong $(>50 \%)$ reaction). The content of extracellular collagen was estimated using the chromotrope-aniline blue (CAB; score 0-3 for negative to strong staining) (31). 
Table I. Cell cycle and growth characteristics of BTC cell lines.

\begin{tabular}{|c|c|c|c|c|c|c|c|}
\hline \multirow[b]{2}{*}{ Cell line } & \multirow[b]{2}{*}{$\begin{array}{l}\text { Original tumour } \\
\text { grading }\end{array}$} & \multicolumn{4}{|c|}{ Cell cycle distribution ${ }^{\mathrm{a}}$} & \multicolumn{2}{|c|}{ Growth curve $^{c}$} \\
\hline & & $\mathrm{G}_{0} / \mathrm{G}_{1}$ & $\mathrm{~S}$ & $\mathrm{G} 2$ & $(\mathrm{~S}+\mathrm{G} 2)^{\mathrm{b}}$ & Slope & $\mathrm{R}^{2}$ \\
\hline CCLP-1 & G3 & $57.0 \pm 5.5$ & $20.5 \pm 1.1$ & $23.5 \pm 4.2$ & $44.0 \pm 4.3$ & 5.3 & 0.978 \\
\hline CCSW-1 & G2 & $59.1 \pm 1.1$ & $15.3 \pm 0.5$ & $25.1 \pm 0.0$ & $40.4 \pm 0.5$ & 3.6 & 0.959 \\
\hline $\mathrm{BDC}$ & G4 & $57.4 \pm 4.5$ & $14.5 \pm 0.7$ & $29.3 \pm 2.6$ & $43.8 \pm 2.7$ & 6.5 & 0.981 \\
\hline EGI-1 & G3 & $57.6 \pm 1.4$ & $16.5 \pm 1.0$ & $26.9 \pm 2.2$ & $43.4 \pm 2.4$ & 4.6 & 0.997 \\
\hline MzChA-1 & G1 & $53.2 \pm 0.2$ & $17.3 \pm 4.2$ & $24.8 \pm 0.4$ & $42.1 \pm 4.2$ & 2.6 & 0.925 \\
\hline MzChA-2 & $\mathrm{G} 2$ & $45.3 \pm 0.7$ & $22.5 \pm 1.7$ & $33.4 \pm 0.2$ & $55.9 \pm 1.7$ & 3.7 & 0.922 \\
\hline SkChA-1 & G3 & $56.6 \pm 3.6$ & $17.8 \pm 1.4$ & $25.6 \pm 4.5$ & $43.4 \pm 4.7$ & 3.5 & 0.963 \\
\hline TFK-1 & G2 & $63.4 \pm 6.0$ & $16.8 \pm 4.6$ & $18.4 \pm 0.2$ & $35.2 \pm 4.6$ & 3.7 & 0.964 \\
\hline Wittier & G1 & $59.1 \pm 0.1$ & $19.5 \pm 3.7$ & $19.9 \pm 1.9$ & $39.3 \pm 4.2$ & 3.8 & 0.949 \\
\hline
\end{tabular}

${ }^{\mathrm{a}}$ Given as populations mean \pm STDEV of three independent determinations; ${ }^{\mathrm{b}} \pm$ gaussian errors; ${ }^{\mathrm{c}}$ linear fit of growth curves $($ three independent determinations).

Immunocyto/histochemistry (ICC/IHC). Cell blocks as well as formalin-fixed and paraffin-embedded xenograft tumour samples were cut into $5 \mu \mathrm{m}$ sections and, together with the human BTC tissue microarrays (AccuMax ${ }^{\mathrm{TM}}$ Array, Cat. No. A205; via BioCat, Heidelberg, Germany), deparaffinised using graded alcohols. Antigen retrieval was performed by heat-induced epitope retrieval in $\mathrm{pH} 9.0$ antigen retrieval buffer (Dako, Glostrup, Denmark) at $95^{\circ} \mathrm{C}$ for $60 \mathrm{~min}$. Endogenous peroxidase blocking was carried out for $10 \mathrm{~min}$ with peroxidase-blocking reagent (Dako). Subsequently, primary antibodies were applied for $30 \mathrm{~min}$ at RT. Primary rabbit and mouse antibodies were detected using the EnVision Detection System (Dako), for primary goat antibodies detection was performed using a biotinylated rabbit anti-goat antibody (Dako, 1:400) and StreptABComplex/HRP Duet kit (Dako, 1:300). Visualization was performed using diaminobenzidine (DAB) as the chromogen substrate (Roche Molecular Biochemicals, Mannheim, Germany) according to the manufacturer's instructions. Slides were counterstained with hematoxylin. The stained slides were digitalized using the ImageAccess Enterprise 5 software (Imagic Bildverarbeitung, Glattbrugg, Switzerland). Images were evaluated using a modified quickscore method (32) by multiplication of the intensity (rated $0,1,2,3)$ and extent $(0,1,2,3,4)$ of the staining which yields values ranging from 0 (negative) to maximum 12 (3 staining intensity and $100 \%$ positive cells). Image evaluation was carried out independently by two investigators (TK and DN). Sources of primary antibodies are available on request.

Cytotoxicity and caspase assay. Cells were seeded at a density of $1.5 \times 10^{4}$ per well $\left(2 \times 10^{4}\right.$ for MzChA-1) in 96-well microplates. After $24 \mathrm{~h}$ the cells were washed with $100 \mu \mathrm{l}$ serum-free DMEM and incubated with $100 \mu 1$ medium containing $5 \mu \mathrm{M}$ DMAT or DMSO (solvent control). After $72 \mathrm{~h}$ the medium was replaced with $100 \mu \mathrm{l}$ DMEM containing $0.45 \mathrm{mg} . \mathrm{ml}^{-1} \mathrm{MTT}$ and further processed as described previously (33) (absorbance read at $565 \mathrm{~nm}$ using the Infinite M200). The signal was corrected for blank values and related to untreated control cells; the final values indicate the fraction of intact and metabolically active cells (34). For assay of caspase-3, CCLP-1 and Wittier cells were seeded at a density of $3.29 \times 10^{5}$ and $3.95 \times 10^{5}$ per well in 6-well microplates, respectively. Following $24 \mathrm{~h}$ incubation, cells were washed with serum-free DMEM and incubated with serum-free DMEM containing $5 \mu \mathrm{M}$ DMAT. At time points indicated in Fig. 3C, cells were harvested and cell lysates were assayed for caspase-3 enzyme activity using a fluorigenic AMCDEVD peptide substrate and corrected for overall protein content as described previously (27).

Statistical analysis. Correlation coefficients were calculated according to Spearman using SPSS v. 16.0 (SPSS GmbH Software, Munich, Germany). Univariate ANOVA (analysis of variance) was used to test for differences between groups of tissue samples. Student's t-test was used for comparison of viability signals.

\section{Results}

In vitro proliferation characteristics. Proliferative characteristics by cell cycle and growth analysis indicate high proliferative capacity of all BTC cell lines with the BDC cell line characterized by the highest rate of proliferation (Table I). Analysis of the cell cycle distribution by flow cytometry largely corresponds to the growth curves obtained for the individual cell lines.

$m R N A$ and protein expression analyses

In vitro analysis (Fig. 1). For Wnt ligands, only mRNA specific for Wnt3 could be amplified by qRT-PCR (Fig. 1A); Furthermore, Lef1 as a transcriptional effector could be detected and quantified only in CCSW-1, EGI-1, MzChA-1 and SkCHA-1 cells. Other components of the Wnt pathway 

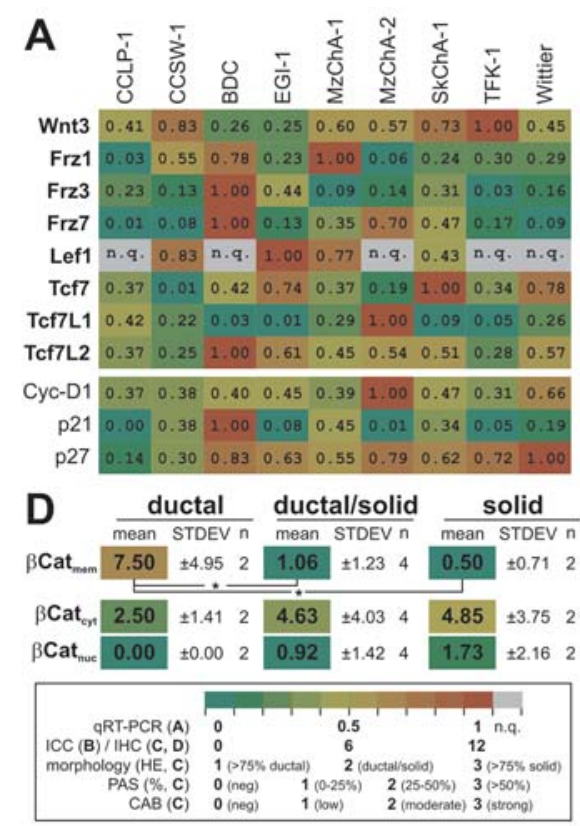
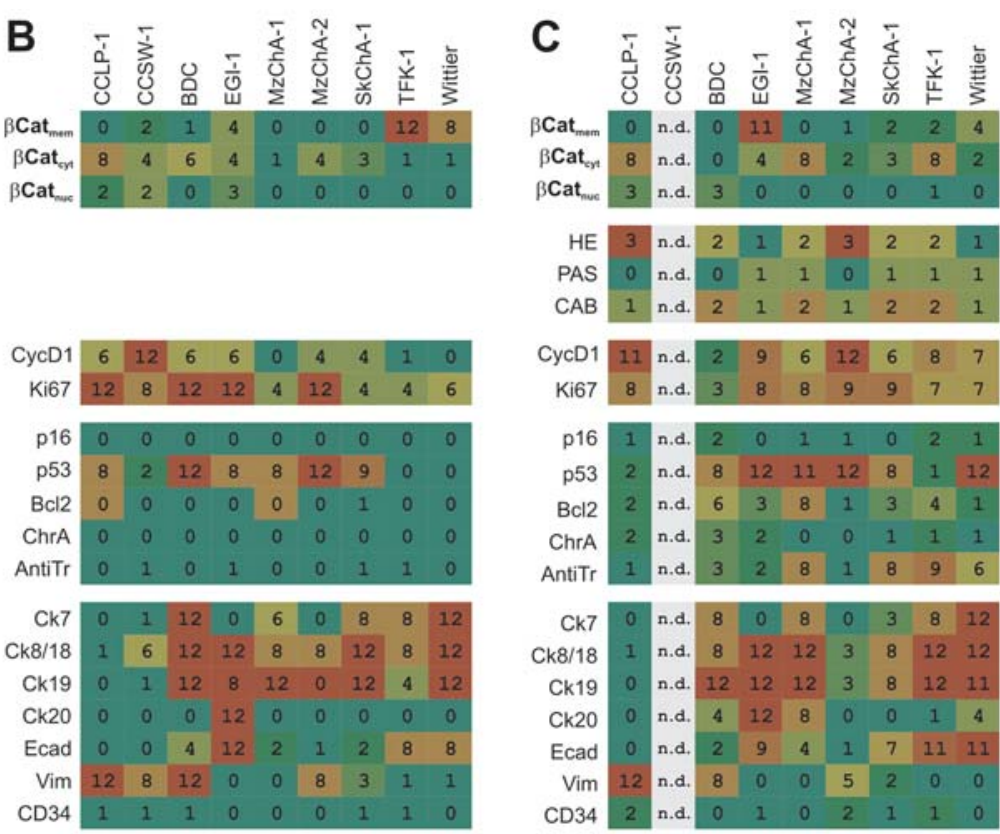

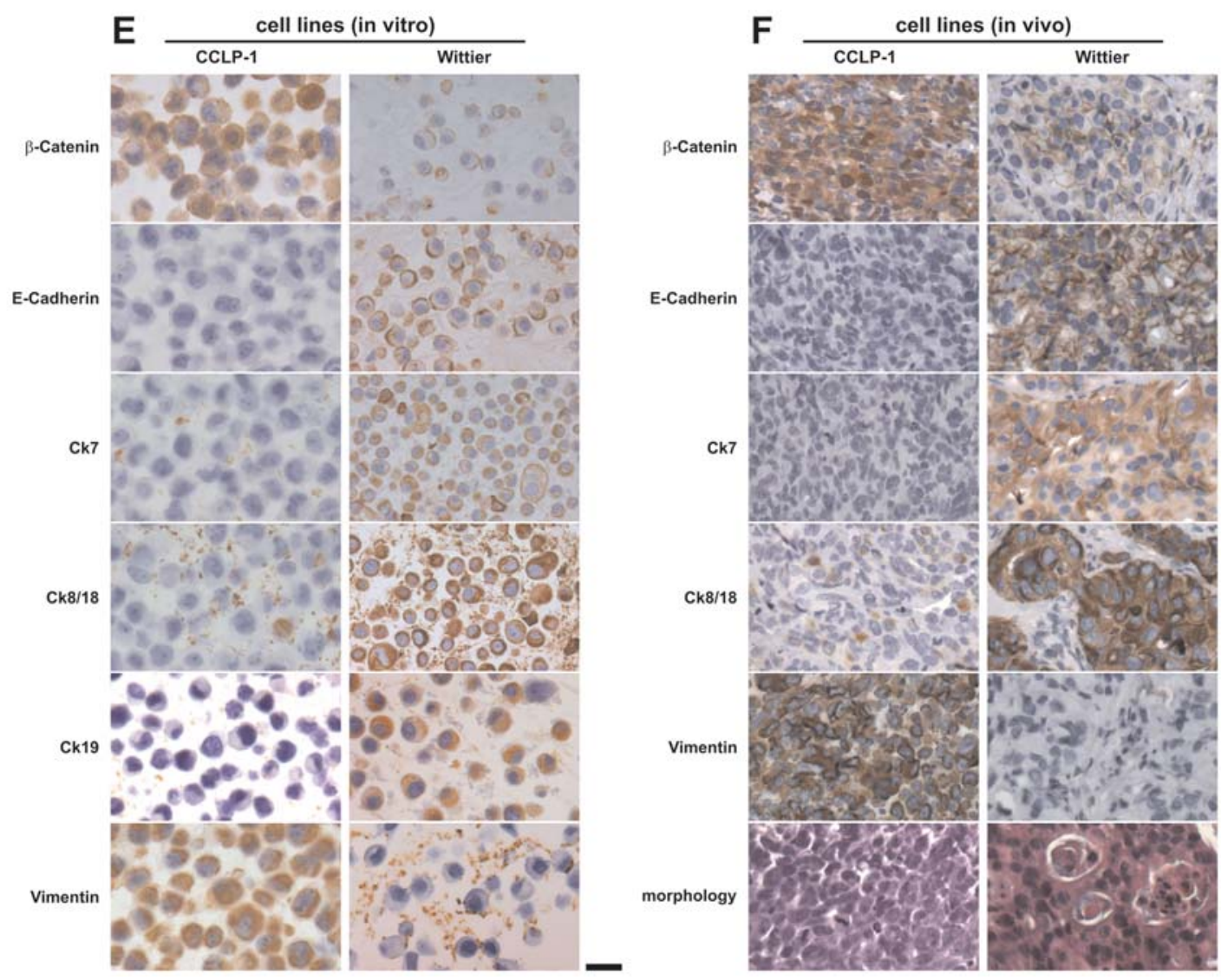

Figure 1. Expression analysis. mRNA of Wnt pathway components was analyzed by qRT-PCR (A) and general cellular markers as well as the localisation of BCat by immunocytochemistry in vitro (B) and immunohistochemistry in vivo (C). (A) the level of mRNA expression is given for each component relative to the cell line with the highest expression level set to 1, mRNAs not quantifiable (n.q.) are shown in grey. (B and C) Semi-quantitative immunochemistry from cell blocks (B) and xenograft tumour (C; n.d., not determined) is given using a modified quickscore method; range 0 (dark green) -12 (red), see Materials and methods section. For both mRNA and protein analysis the colour is indicative of high (red) and low (dark green) expression levels. (D) Morphological analysis for xenograft tumour growth pattern showing differences between intracellular localisation of BCat (one-way ANOVA). (E and F) Representative immunochemistry images of $\beta C$ at and general cellular makers for two cell lines, CCLP-1 and Wittier in vitro (E; x400 magnification, $20 \mu \mathrm{m}$ scale bar) and in vivo (F; x400 magnification, $20 \mu \mathrm{m}$ scale bar).

such as the $\operatorname{Frz}(-1 /-3 /-7)$ receptor molecules and the Tcf(-7/ $-7 \mathrm{~L} 1 /-7 \mathrm{~L} 2)$ transcriptional effectors were detected in all 9 cell lines without an obvious predominant pattern. For example, generally high levels of the Frz receptors were found in the BDC cell line contrasting the CCLP-1, TFK-1 and Wittier cells in which these transcripts are found only at 
Table II. Correlation analysis in vitro.

\begin{tabular}{|c|c|c|}
\hline $\begin{array}{l}\text { Wnt com- } \\
\text { ponent }\end{array}$ & $\begin{array}{c}\text { Positive } \\
\text { correlation }^{\mathrm{c}}\end{array}$ & $\begin{array}{l}\text { Negative } \\
\text { correlation }^{\mathrm{c}}\end{array}$ \\
\hline$\beta C a t^{b}{ }_{\text {mem }}$ & $\mathrm{ECad}^{\mathrm{b}}, \mathrm{G}_{0}+\mathrm{G}_{1}$ (cell cycle) & $\begin{array}{l}\mathrm{p} 53^{\mathrm{b}}, \mathrm{S}+\mathrm{G}_{2} \\
\text { (cell cycle) }\end{array}$ \\
\hline$ß \mathrm{Cat}_{\mathrm{cyt}}^{\mathrm{b}}$ & $\begin{array}{c}\text { Grading, Vim }{ }^{\mathrm{b}}, \text { slope } \\
\text { (growth curve), } \mathrm{S}+\mathrm{G}_{2} \\
\text { (cell cycle), CycD } 1^{\mathrm{b}}, \mathrm{Ki}^{\mathrm{b}} \mathrm{b}\end{array}$ & \\
\hline $\mathrm{BCat}^{\mathrm{b}}{ }_{\text {nuc }}$ & $\operatorname{Vim}^{\mathrm{b}}, \mathrm{CycD}^{\mathrm{b}}$ & \\
\hline Wnt $3^{\mathrm{a}}$ & & $\begin{array}{c}\text { Slope (growth curve), } \\
\text { Ki67 }^{\mathrm{b}}\end{array}$ \\
\hline Frz $1^{a}$ & $\mathrm{p} 21^{\mathrm{a}}$ & $\mathrm{S}$ (cell cycle) \\
\hline Frz3 $^{a}$ & Grading & \\
\hline Frz7a & $\mathrm{p} 53^{\mathrm{b}}$ & \\
\hline $\operatorname{Tcf} 7^{\mathrm{a}}$ & $\mathrm{Ck} 8 / 18^{\mathrm{b}}$ & \\
\hline Tcf7L $1^{\mathrm{a}}$ & $\mathrm{S}$ (cell cycle) & $\mathrm{ECad}^{\mathrm{b}}$ \\
\hline Tcf7L2 ${ }^{\mathrm{a}}$ & $\mathrm{Ck} 8 / 18^{\mathrm{b}}, \mathrm{CycD} 1^{\mathrm{a}}, \mathrm{p} 27^{\mathrm{a}}$ & \\
\hline \multicolumn{3}{|c|}{$\begin{array}{l}{ }^{a} \mathrm{qRT}-\mathrm{PCR} \text { (Fig. 1A); }{ }^{\mathrm{b} I m m u n o c y t o c h e m i s t r y, ~ c e l l ~ b l o c k s ~(F i g . ~ 1 B) ; ~} \\
{ }^{\mathrm{p}} \mathrm{p}<0.05 \text {. Cat, catenin; Ck, cytokeratin; Cyc, cyclin; cyt, } \\
\text { cytoplasmatic; ECad, E-cadherin; Frz, frizzled; mem, membranous; } \\
\text { nuc, nuclear; Tcf, transcription factor (T cell-specific); vim, } \\
\text { vimentin. }\end{array}$} \\
\hline
\end{tabular}

low levels. At the protein level (Fig. 1B) the expression and intracellular localisation of BCat shows i) varying pattern between individual cell lines, and ii) a distinct reciprocal staining pattern, i.e. cell lines with predominantly membranelocalizing BCat (Egi-1, TFK-1 and Wittier) show small scores for cytoplasmatic or nuclear staining and vice versa. Representative images of $ß$ Cat staining patterns for cell blocks are shown in Fig. 1E.

The intracellular localisation of BCat in the different BTC cell lines is associated with the expression of differentiation markers as follows: predominant membranous $ß$ Cat expressing cells such as Wittier and TFK-1 show high Ck7, -8/18, -19 and E-cadherin, but low levels of vimentin whereas mainly cytoplasmatic BCat expressing cells such as CCLP-1 show low expression of cytokeratins and E-cadherin, but high levels of vimentin (see also below for correlation analysis).

In vivo analysis (xenograft) (Fig. $1 C$ and $F$ ). For several cell lines this trend of $ß C$ at expression is preserved also for xenograft tumours. Similar to the above-mentioned results predominantly membranous localising BCat is seen in cell lines with high cytokeratins as well as E-cadherin and vice versa. Additionally, as shown in Fig. 1D, membranous BCat expression decreases from ductal to solid growth pattern whereas cytoplasmatic and nuclear BCat shows an opposite trend. In general, the cell lines can be classified from Fig. 1B and $\mathrm{C}$ into two groups by low versus high differentiation characteristics, a distinction which is in line also with xenograft tumour morphology (HE staining) and proliferation status.
Table III. Correlation analysis in xenograft tumours.

\begin{tabular}{|c|c|c|}
\hline $\begin{array}{l}\text { Wnt com- } \\
\text { ponent }\end{array}$ & $\begin{array}{c}\text { Positive } \\
\text { correlation }^{\mathrm{d}}\end{array}$ & $\begin{array}{l}\text { Negative } \\
\text { correlation }^{\mathrm{d}}\end{array}$ \\
\hline$\beta C a t^{b e m}$ & Ecad $^{c}$ & Morphology $(\mathrm{HE})^{\mathrm{c}}$ \\
\hline$B C \mathrm{Ct}^{\mathrm{c}}{ }_{\mathrm{mem}}$ & Ecad $^{c}$ & \\
\hline$\beta C a t^{b}{ }_{\text {cyt }}$ & $\operatorname{Vim}^{\mathrm{c}}$ & $\begin{array}{l}\text { PAS }^{c} \text { AntiTr }^{c} \\
\text { Ck8/18 } \text { Ecad }^{\mathrm{c}}\end{array}$ \\
\hline$B C a t^{c}{ }_{c y t}$ & & $\mathrm{p} 27^{\mathrm{a}}$ \\
\hline$\beta C a t^{c}{ }_{n u c}$ & $\operatorname{Vim}^{\mathrm{c}}$ & $\mathrm{PAS}^{\mathrm{c}}$ \\
\hline Frz1 $^{\mathrm{a}}$ & $\begin{array}{c}\mathrm{CAB}^{\mathrm{c}}, \mathrm{AntiTr}^{\mathrm{c}}, \mathrm{Ck} 7^{\mathrm{c}}, \\
\mathrm{Ck} 19^{\mathrm{c}}, \mathrm{Bcl}^{\mathrm{c}}\end{array}$ & $\mathrm{CycD}^{\mathrm{c}}$ \\
\hline Tcf7L $1^{\mathrm{a}}$ & & $\mathrm{Ck} 19^{\mathrm{c}}$ \\
\hline
\end{tabular}

${ }^{a}$ qRT-PCR (Fig. 1A); ' Immunocytochemistry, cell blocks (Fig. 1B); Immunohistochemistry, xenograft tumours (Fig. 1C); ${ }^{\mathrm{d}} \mathrm{p}<0.05$. AntiTr, $\alpha 1$-antitrypsin; CAB, chromotrope-aniline blue; Cat, catenin; Ck, cytokeratin; Cyc, cyclin; cyt, cytoplasmatic; ECad, Ecadherin; Frz, frizzled; mem, membranous; nuc, nuclear; Tcf, transcription factor ( $\mathrm{T}$ cell-specific); vim, vimentin.

Representative images for in vitro and in vivo samples are shown in Fig. 1E and F, respectively.

In vivo analysis (TMA, Fig. 2). Immunohistochemistry revealed significant differences between normal and BTC cases for BCat localisation (Fig. 2C): for normal tissue BCat expression was almost exclusively found in the cell membrane whereas BTC tissue samples showed reduced membranous and increased cytoplasmatic $3 \mathrm{Cat}$ localisation, that corresponded to decreased $\mathrm{Ck} 7$ and increased expression of Ki67 $(\mathrm{p}<0.01)$ and vimentin $(\mathrm{p}<0.05)$ (Fig. 2A). Analysis by tumour morphology showed a decreasing membranous localisation of BCat from ductal over mixed (solid/ductal) to solid growth pattern (Fig. 2D), and an opposite trend for cytoplasmatic BCat, which was, however not statistically significant. The three different morphologic tumour types differed significantly in the expression of $\mathrm{Ck} 8 / 18$, vimentin and Ki67, as well as in their grading and TNM categories (Fig. 2B). Representative IHC images for TMA samples are shown in Fig. 2E.

\section{Correlation analysis}

In vitro (Table II). With respect to Wnt pathway activation a number of significant correlations consistently indicates that membranous localisation of $\mathrm{BCat}$ (inactive Wnt signalling) is linked with high differentiation (positive correlation with Ecadherin) and low proliferation (positive and negative correlation with $\mathrm{G}_{0} / \mathrm{G}_{1}$ and $\mathrm{S} / \mathrm{G}_{2}$ cell cycle populations, respectively). Cytoplasmatic and nuclear localisation of $B C$ at, on the contrary, is associated with high proliferation (positive correlation with growth curve, $\mathrm{S} / \mathrm{G}_{2}$, cyclin D1, Ki67 and low p27) and low or mesenchymal differentiation (positive 
A

\begin{tabular}{|c|c|c|c|c|c|}
\hline & normal & & & BTC & \\
\hline & mean STDEV & & mean & STDEV & $n$ \\
\hline Ck7 & \pm 0.00 & 4 & 6.22 & \pm 3.74 & 78 \\
\hline k8/18 & $2.00 \pm 0.00$ & 4 & 8.60 & \pm 3.42 & 78 \\
\hline Ck19 & $2.00 \pm 0.00$ & 4 & 8.72 & \pm 3.32 & 78 \\
\hline Vim & \begin{tabular}{c|c}
1.50 & \pm 0.58
\end{tabular} & 4 & 3.92 & \pm 3.04 & 78 \\
\hline Ki67 & \pm 0.50 & 4 & 1.6 & \pm 0.84 & 78 \\
\hline
\end{tabular}

B ductal ductal/solid $\quad$ solid

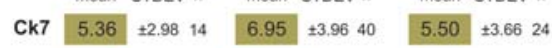



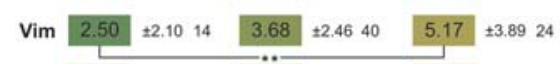



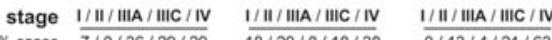

\% cases $7 / 0 / 36 / 29 / 29 \quad 18 / 20 / 8 / 18 / 38 \quad 0 / 13 / 4 / 21 / 63$

$\underset{\% \text { cases }}{\operatorname{grading}} \frac{1 / 2 / 2-3 / 4}{36 / 50 / 14 / 0} \quad \frac{1 / 2 / 2-3 / 4}{13 / 73 / 5 / 10} \quad \frac{1 / 2 / 2-3 / 4}{8 / 54 / 0 / 38}$

$T$
\% cases $\frac{1 / 2 / 3 / 4}{7 / 14 / 64 / 14} \quad \frac{1 / 2 / 3 / 4}{18 / 45 / 33 / 5} \quad \frac{1 / 2 / 3 / 4}{8 / 42 / 50 / 0}$

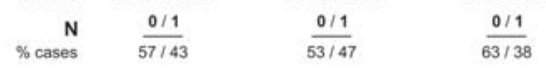

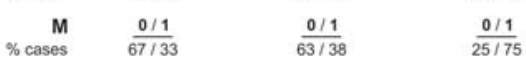

E

$\beta$-Catenin

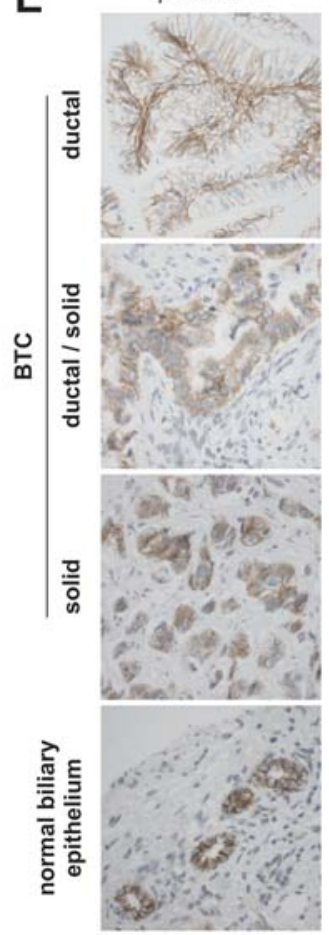

Ck7

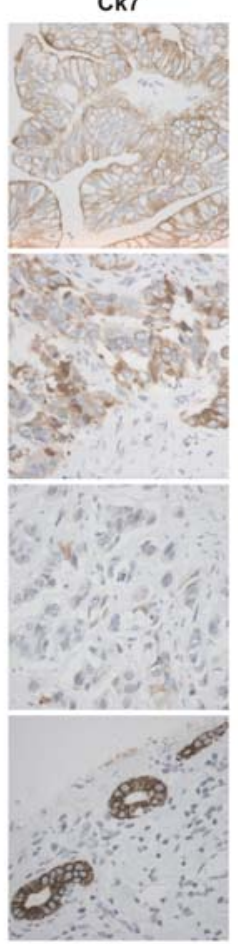

Ck8/18

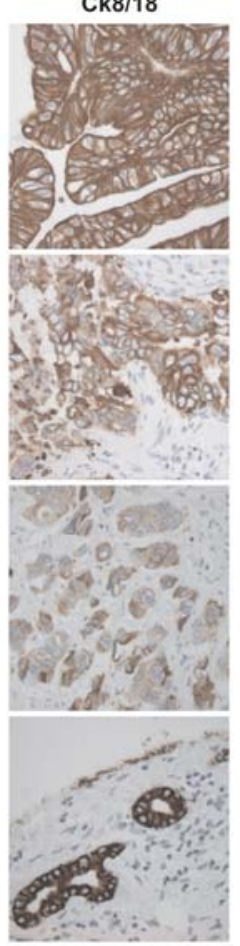

C

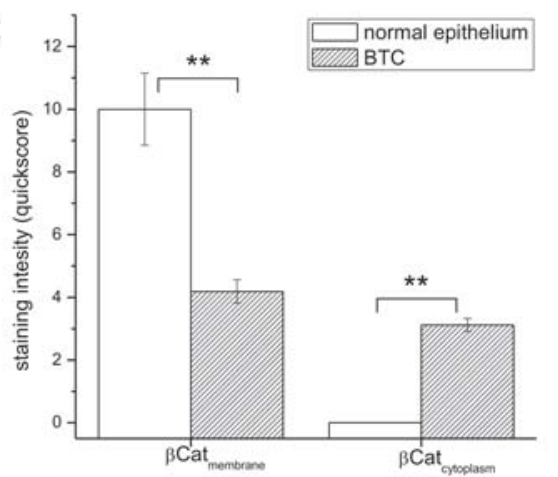

D

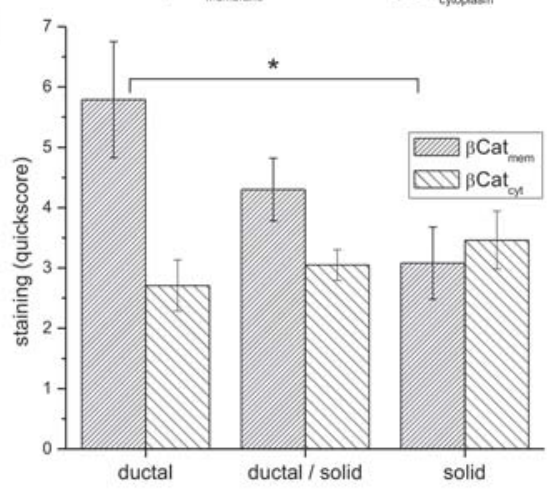

Ck19


Ki67

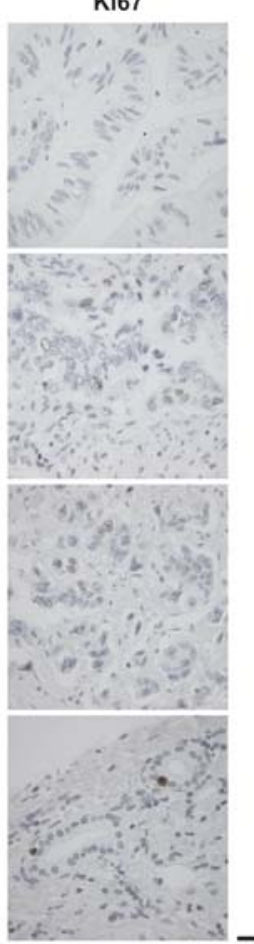

Figure 2. Expression pattern in human BTC TMAs. (A) Human tissue microarrays were evaluated using a subset of markers and results are given as mean values for BTC and normal tissue sample, respectively. (B) Detailed morphological classification showing results for IHC markers (significant differences between groups with ${ }^{*} \mathrm{p}<0.05$ and ${ }^{* *} \mathrm{p}<0.01$, respectively) and clinicopathological parameters. (C) The extent of membranous or cytoplasmatic $B$ Cat localisation is shown for normal biliary epithelium and BTC (mean \pm SEM) and compared using ANOVA (highly significant differences, ${ }^{* *}$ p $<0.01$ ). (D) Staining intensities for cytoplasmatic/membraneous BCat in BTC samples with ductal, mixed (solid/ductal) and solid morphology (mean \pm SEM; significant differences, ${ }^{*}$ p $<0.05$ ). (E) Representative IHC images for different morphological classes of BTC cases (x400 magnification, $20 \mu \mathrm{m}$ scale bar).

correlation with grading and vimentin). Comparison of differentiation and proliferation parameters in vitro confirmed these relationships: in particular, high differentiation status (by high cytokeratin and E-cadherin and low vimentin expression) is linked with low proliferation capacity, as measured by growth curve, cell cycle distribution and proliferation markers (cyclin D1, Ki67) or with expression of cell cycle inhibitors (p21, p27) (data not shown). 

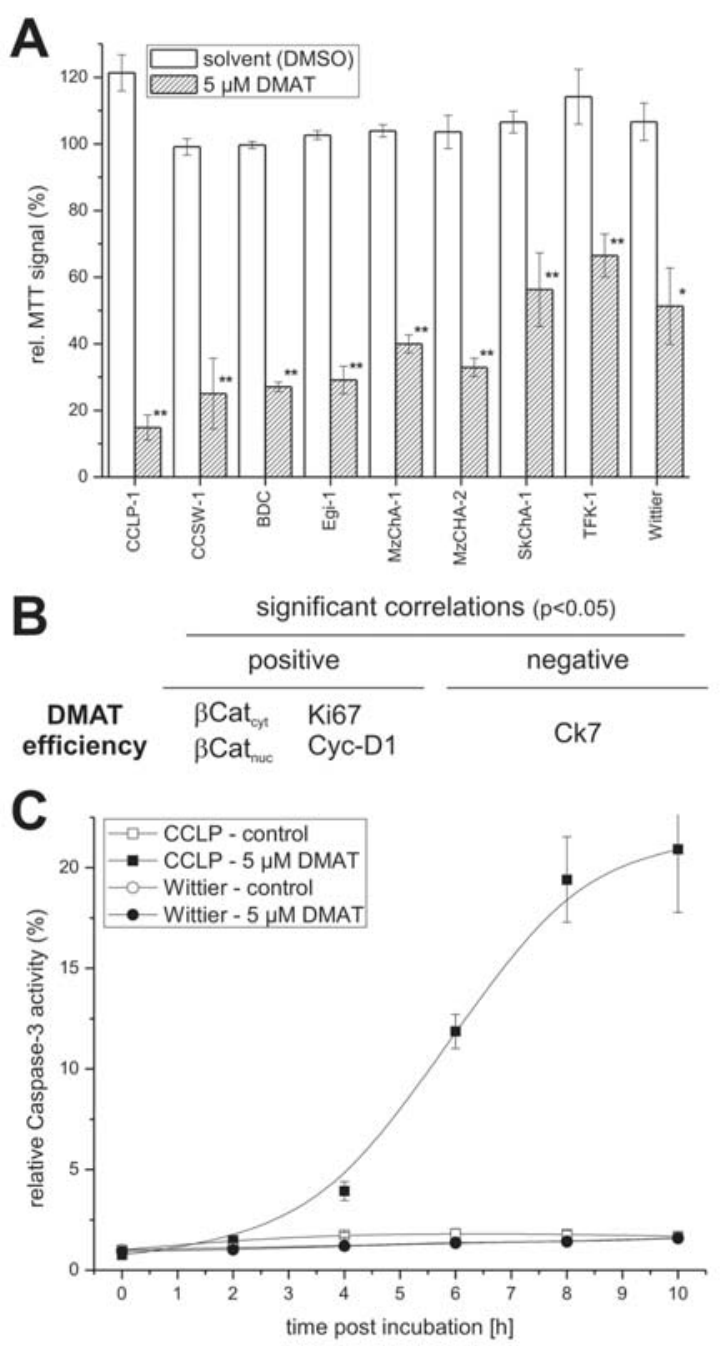

D



Figure 3. Cytotoxic effects of pathway inhibition. (A) Cells were incubated with $5 \mu \mathrm{M}$ DMAT for $72 \mathrm{~h}$ and tested by the MTT assay for overall cellular viability. Values represent means \pm SEM for 3 independent experiments relative to untreated controls (set to $100 \%$ ), Significantly ${ }^{*} \mathrm{p}<0.05$ and highly significantly ${ }^{* *} \mathrm{p}<0.01$ different compared to the respective solvent controls. (B) Correlation analysis of the efficiency of DMAT and the in vitro characteristics (Fig. 1B). (C) Time-course analysis of caspase-3 enzymatic activity indicative of apoptotic cell death in the CCLP-1 and Wittier cell lines following incubation with or without $5 \mu \mathrm{M}$ DMAT. Values represent mean values of three independent determinations \pm SEM relative to initial values $(0 \mathrm{~h})$. (D) Immunochemical analysis of BCat in CCLP-1 cells treated for $5 \mathrm{~h}$ with $5 \mu \mathrm{M}$ DMAT. Representative images (x1000 magnification) showing regions with low (top) or high (bottom) cell density; scale bar $10 \mu \mathrm{m}$. Values represent mean values \pm SEM of BCat-reactive cells from 5 different image sections, ${ }^{* *} \mathrm{p}<0.01$, highly significant difference.
In vivo (Table III). For differentiation parameters similar relationships were found in xenograft tumours. A solid tumour morphology or PAS reactivity correlated with cytoplasmatic and nuclear localising $\mathrm{BCat}$, and membranous localisation of BCat corresponded to E-cadherin expression and tumour differentiation. Notably, the mRNA levels of Wnt pathway components (Tcf7 transcription factors and Frz receptors) are often contrary to those of membranous BCat, as shown for both the in vitro and in vivo situation (Tables II and III).

Human tissue microarray (Table IV). IHC analysis of human BTC TMAs confirmed the above-mentioned relationship between Wnt pathway activation and dedifferentiation status (Fig. 2). As shown in Table IV, membranous localisation of BCat (inactive Wnt pathway) shows positive correlation with $\mathrm{Ck} 8 / 18$ and negative correlations with vimentin, tumour grading and advanced tumour stage or metastasis status. Localisation of $B C$ at in the membrane vs. cytoplasm shows an inverse relationship; cytoplasmatic $B$ Cat is correlated with Ki67, however, without reaching statistical significance $(\mathrm{p}=0.065)$.

Effects of Wnt pathway inhibition. In order to investigate whether pharmacological pathway inhibition affects cell viability in vitro, cells were incubated for $72 \mathrm{~h}$ with DMAT to inhibit Wnt signalling. This period of drug incubation was chosen to ensure that the MTT signal represents the remaining viable cell fraction at a time point when apoptotic cells no longer contribute to the MTT signal (35). In preliminary experiments (data not shown) dose-response analyses were performed and the indicated concentration elicited reproducible and significant cytotoxicity. As shown in Fig. 3A, $5 \mu \mathrm{M}$ DMAT caused a significant decrease in the MTT signal compared to solvent controls in all cell lines, ranging from about $50 \%$ (SkChA-1, TFK-1, Wittier) to $>90 \%$ reduction (CCLP-1).

When the cytotoxic efficiency was compared with proliferation and differentiation parameters (Fig. 3B) we found significant positive correlation with cyclin D1 and Ki67 staining as well as negative correlation with Ck7. Interestingly, both cytoplasmatic and nuclear localisation of BCat was significantly associated with high cytotoxic effects of DMAT. Time-course analysis of the caspase- 3 enzymatic activity (Fig. 3C) further indicates that the reduction of viability by DMAT is caused by induction of apoptosis. In CCLP-1 cells the caspase- 3 signal reaches a maximum after 8-10 h post incubation with DMAT. In Wittier cells where DMAT is less effective the caspase- 3 signal is in range of control sample at all time points analysed. In order to verify DMAT as a specific inhibitor of Wnt signalling, cells treated with $5 \mu \mathrm{M}$ DMAT were probed for BCat by immunocytochemistry $5 \mathrm{~h}$ post incubation (Fig. 3D). As indicated by arrows, about $35 \%$ of DMAT-treated cells show complete non-reactivity for BCat whereas almost all cells in control samples (>97\%) showed intense cytoplasmatic and nuclear staining.

\section{Discussion}

The analysis of Wnt pathway expression in nine different BTC cell lines in cell culture and xenograft tumours as well as in 
Table IV. Correlation analysis in tissue microarrays.

Correlation

$\left({ }^{\mathrm{a}} \mathrm{p}<0.05\right.$ and $\left.{ }^{\mathrm{b}} \mathrm{p}<0.01\right)$

\begin{tabular}{|c|c|c|}
\hline & & \\
\hline & Positive & Negative \\
\hline$B C a t_{\text {mem }}$ & $\mathrm{Ck} 8 / 18^{\mathrm{b}}$ & $\mathrm{M}^{\mathrm{b}}$, stage $^{\mathrm{b}}$, morpho $(\mathrm{HE})^{\mathrm{a}}, \mathrm{Vim}^{\mathrm{b}}, \mathrm{BCat}_{\mathrm{cyt}}^{\mathrm{b}}$ \\
\hline$ß \mathrm{Cat}_{\mathrm{cyt}}$ & $\operatorname{Ki}^{\text {n.s. }}(p=0.065)$ & $ß C a t_{\text {mem }}{ }^{b}$ \\
\hline Grading & Morpho $(\mathrm{HE})^{\mathrm{b}}, \mathrm{Vim}^{\mathrm{a}}, \mathrm{Ki}^{\mathrm{b}}{ }^{\mathrm{b}}$ & \\
\hline $\mathrm{T}$ & $\mathrm{N}^{\mathrm{b}}, \mathrm{M}^{\mathrm{b}}$ & \\
\hline $\mathrm{N}$ & $\mathrm{T}^{\mathrm{b}}$ & \\
\hline M & $\mathrm{T}^{\mathrm{b}}$, stage $^{\mathrm{b}}$, morpho $(\mathrm{HE})^{\mathrm{b}}, \mathrm{Ki}^{\mathrm{b}}{ }^{\mathrm{b}}$ & $ß C \mathrm{Cat}_{\mathrm{mem}}^{\mathrm{b}}$ \\
\hline Stage & $\mathbf{M}^{\mathrm{b}}$, morpho $(\mathrm{HE})^{\mathrm{a}}, \mathrm{Ki}^{6} 7^{\mathrm{b}}$ & $ß C \mathrm{Cat}_{\mathrm{mem}^{\mathrm{b}}}^{\mathrm{b}}$ \\
\hline Morpho (HE) & Grading $^{\mathrm{b}}, \mathrm{M}^{\mathrm{b}}$, stage $^{\mathrm{b}}, \mathrm{Vim}^{\mathrm{a}}$ & $\mathrm{Ck} 8 / 18^{\mathrm{b}}, \mathrm{BCat}_{\mathrm{mem}^{\mathrm{a}}}$ \\
\hline $\mathrm{Ck} 7$ & $\mathrm{Ck} 8 / 18^{\mathrm{b}}, \mathrm{Ck} 19^{\mathrm{b}}$ & \\
\hline $\mathrm{Ck} 8 / 18$ & $\mathrm{Ck} 7^{\mathrm{b}}, \mathrm{Ck} 19^{\mathrm{b}}, \mathrm{BCat}_{\mathrm{mem}^{\mathrm{a}}}$ & Morpho $(\mathrm{HE})^{\mathrm{b}}, \mathrm{Vim}^{\mathrm{b}}$ \\
\hline Ck19 & $\mathrm{Ck} 7^{\mathrm{b}}, \mathrm{Ck} 8 / 18^{\mathrm{b}}$ & $\operatorname{Vim}^{\mathrm{a}}$ \\
\hline Vim & Grading $^{\mathrm{a}}$, morpho $(\mathrm{HE})^{\mathrm{a}}$ & $\mathrm{Ck} 8 / 18^{\mathrm{b}}, \mathrm{Ck} 19^{\mathrm{a}}, \mathrm{Cat}_{\mathrm{mem}^{\mathrm{b}}}$ \\
\hline Ki67 & Grading $^{\mathrm{b}}, \mathrm{M}^{\mathrm{b}}$, stage $^{\mathrm{b}}$ & \\
\hline
\end{tabular}

Cat, catenin; Ck, cytokeratin; cyt, cytoplasmatic; mem, membranous; morpho, morphology; n.s., not significant; Vim, vimentin.

human BTC tissue microarrays yielded three major findings: i) the Wnt pathway is functional to a different degree in all cell lines and in human BTC TMA, ii) activation of the Wnt pathway correlates with decreasing differentiation and increasing proliferation status of BTC, both in vitro and in vivo as well as in human BTC tissues, and iii) pharmacologic inhibition of the Wnt pathway is highly cytotoxic for BTC cells in vitro.

In order to analyse whether the Wnt pathway is active in the experimental BTC model we studied the localisation of BCat. Accumulation of cytoplasmatic and nuclear BCat induced by down-regulation of the cytoplasmatic destruction complex is the defining event of active Wnt signalling (1113). Based on this criterion we found that the Wnt pathway is either inactive (preferential membranous BCat) or active with predominant cytoplasmatic or nuclear $B$ Cat each in a subgroup of the cell lines. This feature is also maintained in corresponding xenograft tumours showing similar grouping of cell lines according to their BCat localisation. Active Wnt signalling is further confirmed by positive correlation of cytoplasmatic and nuclear BCat with the growth characteristics, both in vitro and in xenograft tumours, in accordance with the cell cycle-promoting effect of the activated Wnt pathway on gene transcription level.

Cyclin D1 is a well-established target gene of active Wnt signalling $(11,15,36)$, and a growth-promoting mechanism has already been shown for other gastrointestinal tumours $(12,37)$. In agreement with our results, nuclear or cytoplasmatic BCat was found in $>50 \%$ of cases with intrahepatic cholangiocarcinoma ( $n=14$ out of 24) and the levels of cyclin D1 and tumour size were correlated with BCat accumulation (38). Possibly due to the small number of cases, no significant relations could be found between $B C$ at and tumour differentiation or the macroscopic and histological type (38). Furthermore, we found an inverse relation of mRNA level of the cyclin-dependent kinase inhibitor p27 $7^{\mathrm{KIP} 1}$ and the amount of cytoplasmatic BCat (Table II), indicating that the expression of $\mathrm{p} 27$ (KIP1) could be controlled by Wnt in BTC cells. The p27 protein has been described as a negative Wnt target $(39,40)$. For the mRNA level of Wnt receptors or transcription factors we could not find similar correlations (Tables II and III). This discrepancy might be explained by the fact that activation of the Lef/Tcf-like transcription factors by association with nuclear $B$ Cat does not necessarily alter the relative amount of these transcription factors. As discussed below, further evidence for Wnt activation in BTC is provided by the significant cytotoxic effects exerted by pharmacological inhibition in BTC cell lines.

When the localisation of BCat was related to the histological differentiation of the cell lines we found several significant correlations: increased cytoplasmatic or nuclear ßCat is significantly associated with poor differentiation (high grading) of the original tumour (Table II), reduced Ecadherin (Tables II and III) and a solid growth type of the xenograft tumour (Table III). This finding is supported by Settakorn et al (41) who found that reduced membranous $ß C$ at is significantly linked to reduced membranous Ecadherin. Additionally, our analysis indicates that active Wnt signalling is connected with a transition to a mesenchymal phenotype as well as dedifferentiation (high vimentin and low cytokeratin expression, Table III). The latter is supported by data on other tumour types where disruption of Wnt signalling by a dominant negative Tcf-4 resulted in G1 cell cycle arrest and intestinal differentiation of colorectal cancer cells (42), and reduced membranous BCat was linked to loss of differentiation in thyroid tumours (43). 
In actual human BTC tissue samples analysis of Wnt pathway activation via BCat localisation confirmed the key findings of the cell line model. We found that membranous $B C$ at is significantly decreased when compared to normal biliary epithelium, whereas cytoplasmatic BCat is frequently found in BTC tissues. These results are in line with published data showing that membranous $B C$ at is reduced compared to normal biliary epithelium $(38,44,45)$ and correlated with loss of differentiation in cancer cells (44) and histological tumour type (45), and progression in biliary intraepithelial neoplasia (BilIN) and intraductal papillary neoplasm of the bile duct (IPNB) (46). We further demonstrate that membranous $ß$ Cat is linked with high $\mathrm{Ck} 8 / 18$ expression and inversely correlated with advanced tumour stage or metastasis status. For both, human BTC and the xenograft model, we found a consistent connection between BCat localisation and the tumour morphology. In particular, reduced membranous and increasing cytoplasmatic BCat is associated with a solid pattern of tumour morphology. As no detailed case history is available for the commercial TMAs used in this study, further analysis for e.g. survival time cannot be provided with these samples. The current study did not address the mutational status of Wnt components. For BTC, published results on mutations in Wnt components are rather controversial. Particularly, mutations in the BCat, APC and Axin-1 gene were found in some cases of intrahepatic cholangiocarcinoma (38) whereas others studies $(45,47)$ failed to do so. Therefore, comprehensive studies on the impact of pathwayactivating mutation in Wnt signalling components for tumourigenesis of BTC seem necessary. Taken together, the present study provides firm evidence from experimental models and human BTC samples that Wnt signalling is deregulated and active in subsets of BTC cases or cell lines.

The association between the mesenchymal marker vimentin and Wnt pathway activation is of special interest, since tumour metastasis is believed to be dependent on an epithelialmesenchymal transition (EMT) providing the cancer cells with cell motility and invasive capacity. Wnt signalling has been implicated in EMT of colon carcinoma (48) and is regarded as one of the important signalling mechanisms to induce EMT $(6,49)$. For the experimental model as well as for human BTC we show a clear correlation between active Wnt signalling and a mesenchymal, i.e. high vimentin phenotype.

To provide data on the potential of Wnt pathways inhibition, we demonstrate DMAT to efficiently reduce viability in all cell lines. DMAT is a cell-permeable inhibitor of casein kinase-2 (CK2) (50) which is crucial for active Wnt signalling (51-53). The functions of CK2 are not restricted to Wnt signalling, e.g. activation of NFKB or PTEN (54), and DMAT is not exclusively specific for CK2 (50). Nevertheless, the cytotoxic effects of DMAT can be attributed to inhibition of Wnt signalling, because the efficiency of DMAT significantly correlated with cytoplasmatic BCat (Fig. 3B). Additionally, DMAT efficiency was high in BTC cells with high proliferation and low cytokeratin immunoreactivity which is in accordance with the above-mentioned relationships between active Wnt pathway and high proliferation or low differentiation status. The specificity to inhibit Wnt signalling is proven by DMAT's ability to down-regulate
BCat in a significant portion of cells (Fig. 3D). To provide insight into the cytotoxic mechanisms of DMAT we analysed the activity of caspase- 3 which is an effector caspase in the apoptotic cascade. For CCLP-1 cells (Fig. 3C) a clear timedependent increase of caspase- 3 activity is observable in contrast to the Wittier cell line for which the cytotoxic effect is much smaller. Taken together, DMAT is highly cytotoxic in BTC cell lines with active Wnt pathway and its cytotoxic effects are mediated by induction of apoptosis.

In summary, we demonstrate that i) the Wnt pathway is active to a different extent in BTC cell lines both in vitro and in vivo, ii) Wnt activation assessed by cytoplasmatic/nuclear localisation of BCat is linked with a phenotype characterized by high proliferation, low differentiation (i.e. low $\mathrm{Ck}$ / E-cadherin expression), mesenchymal features (high vimentin) as well as solid tumour morphology, iii) deregulated/active Wnt signalling can be detected in human BTC samples (tissue microarray) and correlates with aggressive tumour behaviour, and, iv) targeting the Wnt pathway via CK2 inhibition is highly effective in all BTC cell lines, works via induction of apoptotic cell death and the intracellular localisation of BCat is a predictive factor for cytotoxic efficiency. The Wnt pathway therefore is a promising target for future molecular therapy of BTC.

\section{Acknowledgements}

This study was supported by the Jubiläumsfonds der Österreichischen Nationalbank (OeNB, grant No. 12677) and the research fund of the Paracelsus Medical University Salzburg (grant No. 08/07/037). The authors would like to thank Dr K. Plaetzer and Dr J. Berlanda (Department of Molecular Biology, University of Salzburg) and Dr J. Kiesslich and E. Klausriegler (Department of Legal Medicine, University of Salzburg) for valuable technical assistance.

\section{References}

1. Khan SA, Thomas HC, Davidson BR and Taylor-Robinson SD: Cholangiocarcinoma. Lancet 366: 1303-1314, 2005.

2. Lazaridis KN and Gores GJ: Cholangiocarcinoma. Gastroenterology 128: 1655-1667, 2005.

3. Kiesslich T, Wolkersdorfer G, Neureiter D, Salmhofer H and Berr F: Photodynamic therapy for non-resectable perihilar cholangiocarcinoma. Photochem Photobiol Sci 8: 23-30, 2009.

4. Verslype C, Prenen H and Van Cutsem E: The role of chemotherapy in biliary tract carcinoma. HPB (Oxford) 10: 164-167, 2008.

5. Bailey JM, Singh PK and Hollingsworth MA: Cancer metastasis facilitated by developmental pathways: sonic hedgehog, notch, and bone morphogenic proteins. J Cell Biochem 102: 829-839, 2007.

6. Kelleher FC, Fennelly D and Rafferty M: Common critical pathways in embryogenesis and cancer. Acta Oncol 45: 375-388, 2006.

7. Kolligs FT, Bommer G and Goke B: Wnt/beta-catenin/tcf signaling: a critical pathway in gastrointestinal tumorigenesis. Digestion 66: 131-144, 2002.

8. Lees C, Howie S, Sartor RB and Satsangi J: The hedgehog signalling pathway in the gastrointestinal tract: implications for development, homeostasis, and disease. Gastroenterology 129: 1696-1710, 2005

9. Clevers H: Inflating cell numbers by Wnt. Mol Cell 10: 1260-1261, 2002.

10. Kinzler KW and Vogelstein B: Lessons from hereditary colorectal cancer. Cell 87: 159-170, 1996.

11. Lustig B and Behrens J: The Wnt signaling pathway and its role in tumor development. J Cancer Res Clin Oncol 129: 199-221, 2003. 
12. Doucas H, Garcea G, Neal CP, Manson MM and Berry DP: Changes in the Wnt signalling pathway in gastrointestinal cancers and their prognostic significance. Eur J Cancer 41: 365-379, 2005

13. Huang $\mathrm{H}$ and $\mathrm{He} \mathrm{X}$ : Wnt/beta-catenin signaling: new (and old) players and new insights. Curr Opin Cell Biol 20: 119-125, 2008.

14. Miller JR: The Wnts. Genome Biol 3: 3001.1-3001.15, 2002.

15. The Wnt Homepage by 1997-2008 Roel Nusse; URL:http:// www.stanford.edu/ rnusse/wntwindow.html.

16. Ewan KB and Dale TC: The potential for targeting oncogenic WNT/beta-catenin signaling in therapy. Curr Drug Targets 9: 532-547, 2008

17. Garber K: Drugging the Wnt pathway: problems and progress. J Natl Cancer Inst 101: 548-550, 2009.

18. Shimizu Y, Demetris AJ, Gollin SM, et al: Two new human cholangiocarcinoma cell lines and their cytogenetics and responses to growth factors, hormones, cytokines or immunologic effector cells. Int J Cancer 52: 252-260, 1992.

19. Oertel M, Schastak SI, Tannapfel A, et al: Novel bacteriochlorine for high tissue-penetration: photodynamic properties in human biliary tract cancer cells in vitro and in a mouse tumour model. J Photochem Photobiol B 71: 1-10, 2003.

20. Knuth A, Gabbert H, Dippold W, et al: Biliary adenocarcinoma. Characterisation of three new human tumor cell lines. J Hepatol 1: $579-596,1985$

21. Saijyo S, Kudo T, Suzuki M, et al: Establishment of a new extrahepatic bile duct carcinoma cell line, TFK-1. Tohoku J Exp Med 177: 61-71, 1995.

22. Purdum PP 3rd, Ulissi A, Hylemon PB, Shiffman ML and Moore EW: Cultured human gallbladder epithelia. Methods and partial characterization of a carcinoma-derived model. Lab Invest 68: 345-353, 1993

23. Kiesslich T, Berlanda J, Plaetzer K, Krammer B and Berr F: Comparative characterization of the efficiency and cellular pharmacokinetics of Foscan- and Foslip-based photodynamic treatment in human biliary tract cancer cell lines. Photochem Photobiol Sci 6: 619-627, 2007

24. de Groen PC, Gores GJ, LaRusso NF, Gunderson LL and Nagorney DM: Biliary tract cancers. N Engl J Med 341: 1368-1378, 1999.

25. Berman DM, Karhadkar SS, Maitra A, et al: Widespread requirement for hedgehog ligand stimulation in growth of digestive tract tumours. Nature 425: 846-851, 2003.

26. Radonic A, Thulke S, Mackay IM, Landt O, Siegert W and Nitsche A: Guideline to reference gene selection for quantitative real-time PCR. Biochem Biophys Res Commun 313: 856-862, 2004.

27. Oberdanner CB, Kiesslich T, Krammer B and Plaetzer K Glucose is required to maintain high ATP-levels for the energyutilizing steps during PDT-induced apoptosis. Photochem Photobiol 76: 695-703, 2002.

28. Baradari V, Hopfner M, Huether A, Schuppan D and Scherubl H: Histone deacetylase inhibitor MS-275 alone or combined with bortezomib or sorafenib exhibits strong antiproliferative action in human cholangiocarcinoma cells. World J Gastroenterol 13: 4458-4466, 2007.

29. Neureiter D, Zopf S, Dimmler A, et al: Different capabilities of morphological pattern formation and its association with the expression of differentiation markers in a xenograft model of human pancreatic cancer cell lines. Pancreatology 5: 387-397, 2005.

30. Zopf S, Neureiter D, Bouralexis S, et al: Differential response of p53 and p21 on HDAC inhibitor-mediated apoptosis in HCT116 colon cancer cells in vitro and in vivo. Int J Oncol 31: 1391-1402, 2007.

31. Churg J and Prado A: A rapid Mallory trichrome stain (chromotrope-aniline blue). AMA Arch Pathol 62: 505-506, 1956.

32. Detre S, Saclani Jotti G and Dowsett M: A 'quickscore' method for immunohistochemical semiquantitation: validation for oestrogen receptor in breast carcinomas. J Clin Pathol 48: 876-878, 1995.

33. Berlanda J, Kiesslich T, Oberdanner CB, Obermair FJ, Krammer B and Plaetzer K: Characterization of apoptosis induced by photodynamic treatment with hypericin in A431 human epidermoid carcinoma cells. J Environ Pathol Toxicol Oncol 25: 173-188, 2006
34. Mosmann T: Rapid colorimetric assay for cellular growth and survival: application to proliferation and cytotoxicity assays. J Immunol Methods 65: 55-63, 1983.

35. Plaetzer K, Kiesslich T, Krammer B and Hammerl P: Characterization of the cell death modes and the associated changes in cellular energy supply in response to AlPcS4-PDT. Photochem Photobiol Sci 1: 172-177, 2002

36. Behrens J and Lustig B: The Wnt connection to tumorigenesis. Int J Dev Biol 48: 477-487, 2004.

37. Mishra L, Shetty K, Tang Y, Stuart A and Byers SW: The role of TGF-beta and Wnt signaling in gastrointestinal stem cells and cancer. Oncogene 24: 5775-5789, 2005.

38. Tokumoto N, Ikeda S, Ishizaki Y, et al: Immunohistochemical and mutational analyses of Wnt signaling components and target genes in intrahepatic cholangiocarcinomas. Int J Oncol 27: 973-980, 2005.

39. Miranda-Carboni GA, Krum SA, Yee K, et al: A functional link between Wnt signaling and SKP2-independent p27 turnover in mammary tumors. Genes Dev 22: 3121-3134, 2008.

40. Tang Y, Simoneau AR, Liao WX, et al: WIF1, a Wnt pathway inhibitor, regulates SKP2 and c-myc expression leading to G1 arrest and growth inhibition of human invasive urinary bladder cancer cells. Mol Cancer Ther 8: 458-468, 2009.

41. Settakorn J, Kaewpila N, Burns GF and Leong AS: FAT, Ecadherin, beta catenin, HER 2/neu, Ki67 immuno-expression, and histological grade in intrahepatic cholangiocarcinoma. J Clin Pathol 58: 1249-1254, 2005.

42. van de Wetering M, Sancho E, Verweij C, et al: The betacatenin/TCF-4 complex imposes a crypt progenitor phenotype on colorectal cancer cells. Cell 111: 241-250, 2002.

43. Garcia-Rostan G, Camp RL, Herrero A, Carcangiu ML, Rimm DL and Tallini G: Beta-catenin dysregulation in thyroid neoplasms: down-regulation, aberrant nuclear expression, and CTNNB1 exon 3 mutations are markers for aggressive tumor phenotypes and poor prognosis. Am J Pathol 158: 987-996, 2001.

44. Ashida K, Terada T, Kitamura Y and Kaibara N: Expression of E-cadherin, alpha-catenin, beta-catenin, and CD44 (standard and variant isoforms) in human cholangiocarcinoma: an immunohistochemical study. Hepatology 27: 974-982, 1998.

45. Sugimachi K, Taguchi K, Aishima S, et al: Altered expression of beta-catenin without genetic mutation in intrahepatic cholangiocarcinoma. Mod Pathol 14: 900-905, 2001.

46. Itatsu K, Zen Y, Ohira S, et al: Immunohistochemical analysis of the progression of flat and papillary preneoplastic lesions in intrahepatic cholangiocarcinogenesis in hepatolithiasis. Liver Int 27: 1174-1184, 2007.

47. Abraham SC, Lee JH, Hruban RH, Argani P, Furth EE and Wu TT: Molecular and immunohistochemical analysis of intraductal papillary neoplasms of the biliary tract. Hum Pathol 34: 902-910, 2003.

48. Brabletz T, Hlubek F, Spaderna S, et al: Invasion and metastasis in colorectal cancer: epithelial-mesenchymal transition, mesenchymal-epithelial transition, stem cells and beta-catenin. Cells Tissues Organs 179: 56-65, 2005.

49. Moustakas A and Heldin CH: Signaling networks guiding epithelial-mesenchymal transitions during embryogenesis and cancer progression. Cancer Sci 98: 1512-1520, 2007.

50. Pagano MA, Meggio F, Ruzzene M, Andrzejewska M, Kazimierczuk Z and Pinna LA: 2-Dimethylamino-4,5,6,7tetrabromo-1H-benzimidazole: a novel powerful and selective inhibitor of protein kinase CK2. Biochem Biophys Res Commun 321: 1040-1044, 2004.

51. Dominguez I, Sonenshein GE and Seldin DC: CK2 and its role in Wnt and NF-kappaB signaling: linking development and cancer. Cell Mol Life Sci 66: 1850-1857, 2009.

52. Gao Y and Wang HY: Casein kinase 2 Is activated and essential for Wnt/beta-catenin signaling. J Biol Chem 281: 18394-18400, 2006.

53. Seldin DC, Landesman-Bollag E, Farago M, Currier N, Lou D and Dominguez I: CK2 as a positive regulator of Wnt signalling and tumourigenesis. Mol Cell Biochem 274: 63-67, 2005.

54. Duncan JS and Litchfield DW: Too much of a good thing: the role of protein kinase CK2 in tumorigenesis and prospects for therapeutic inhibition of CK2. Biochim Biophys Acta 1784: 33-47, 2008. 